\title{
AS PARTICULARIDADES NA ETNOPOÉTICA DE Márcia Kambeba
}

Rosivânia dos Santos*

https://orcid.org/0000-0002-8893-0610

Como citar este artigo: SANTOS, R. dos. As particularidades na etnopoética de Márcia Kambeba. Todas as Letras - Revista de Lingua e Literatura, São Paulo, v. 22, n. 3, p. 1-14, set./dez. 2020. DOI 10.5935/1980-6914/eLETDO2013511

Submissão: junho de 2020. Aceite: setembro de 2020.

Resumo: Este artigo analisa as etnopoéticas de Márcia Kambeba em sua obra Ay kakyri tama - Eu moro na cidade (2013), avaliando quais mecanismos da linguagem poética utilizados particularizam a forma de escrever da autora, estabelecendo-se, também, uma relação com o "canto" de Graça Graúna e de Eliane Potiguara. A escolha dos poemas de Kambeba como objeto de estudo se deu por se perceber que há uma identidade indígena muito forte nos etnopoemas, agregando-lhes uma riqueza estética. O suporte teórico para este trabalho foi dado por Márcia Kambeba (2012, 2018), Daniel Munduruku (2018) e Ailton Krenak (2019), entre outros. Como resultado desta investigação, percebe-se que há elementos que particularizam as etnopoéticas indigenas, e essas particularidades podem ser consideradas características peculiares de uma escrita dos povos nativos.

Palavras-chave: Etnopoéticas. Márcia Kambeba. Identidade indígena. Graça Graúna. Eliane Potiguara. 


\section{INTRODUÇÃO}

"M árcia Wayna Kambeba é uma poeta indígena de origem Omágua Kambeba, nascida na aldeia Tikuna, no Alto Solimões da Amazônia, atualmente residente em Belém, Pará. Kambeba é professora, escritora, atriz, compositora, cantora, fotógrafa, roteirista, palestrante, contadora de histórias e conselheira do selo ferina ${ }^{1}$. Além disso, possui mestrado em Geografia pela Universidade Federal do Amazonas (Ufam).

Sua dissertação de mestrado foi transformada no livro Ay kakyri tama (2013), que significa "eu moro na cidade", de onde foram retirados os poemas analisados neste artigo. O objetivo de Kambeba com seus poemas é explicar à sociedade que não existe uma cara de índio, existe uma identidade indígena, como posto em suas palavras: "o fundamento de minha produção estética e poética, resumindo tudo, é justamente mostrar às pessoas que não existe uma 'cara de índio', mas que existe uma identidade que o torna pertencente a um "povo" (KAMBEBA, 2018, p. 43).

Vale ressaltar que "indio" é uma invenção dos portugueses gerada por um equívoco, não aquele citado por Oswald de Andrade em seu poema "Erro de português"2, mas, como explica o antropólogo Gersem Baniwa, por acharem que haviam chegado às Índias. Outrossim, a escritora tem em vista esclarecer que o indígena, mesmo saindo de sua aldeia e indo viver na cidade, leva consigo sua territorialidade, sendo compreendida, nesse contexto, como espaço de memória e ancestralidade. O título do livro também é o título de um poema e de um projeto musical ${ }^{3}$, como declarou Kambeba à jornalista Heloisa Aun (2017), do site Catraca Livre. A poeta ainda publicou, no ano de 2018, o livro O lugar do saber, que faz parte da série Saberes Tradicionais.

O livro Ay kakyri tama (2013) está dividido em duas partes: a primeira, intitulada "poemas e crônicas ay kakyritama", é composta por 20 poemas de Kambeba, mesclados com diversas fotografias da própria autora; já a segunda, denominada "participações especiais", é composta por cinco poemas de autorias diversas. A apresentação é feita por Benedito Maciel, e a introdução, pela própria poeta. O livro ganhou uma segunda edição em 2018 pela editora Pólen.

O interesse de Márcia por poesia e música nasceu quando ainda era criança, por influência da sua avó, que além de ser professora em sua aldeia, escrevia poemas e elaborava composições musicais. Com 7 anos de idade, Kambeba já recitava os poemas de sua avó e aos 14 começou a criar os próprios textos poéticos. Dai em diante, tem utilizado sua arte como ferramenta para levar os conhecimentos tradicionais dos povos Kambeba para o Brasil e outras partes do mundo.

\footnotetext{
1 O objetivo desse selo é viabilizar a publicação de livros de autoria feminina que têm dificuldade em encontrar espaços nas editoras. Para mais informações, acessar: http://ferina.com.br/originais/.

2 Erro de português

Quando o português chegou

Debaixo duma bruta chuva

Vestiu o índio

Que pena! Fosse uma manhã de sol

$\mathrm{O}$ índio tinha despido

O português.

3 Este link dá acesso ao curta-metragem Ay kakiri tama, apresentado por Márcia Kambeba com trechos de apresentações musicais: https://www.youtube.com/watch?v=_gq7LY6Z-6U\&feature=youtu.be. Acesso em: 12 abr. 2020.
} 
Para a leitura dos poemas empreendida aqui, foram levantados alguns aspectos que singularizam a poesia indígena - o canto como poética, as etnias como marca de identidade, o autorretrato e o vestígio de fronteira entre a cultura indigena e a não indigena. Esses enfoques são considerados como elementos de suma importância para caracterizar a identidade de uma etnopoética considerada dos povos ancestrais. Assim, a etnopoética, neste artigo, é compreendida pela concepção de Jerome Rothenberg (2006, p. 106) na medida em que, segundo o estudioso, "ela se refere a uma redefinição de poesia em termos de particularidades culturais, com ênfase naquelas tradições alternativas às quais o ocidente deu nomes como 'pagãs', 'gentias', 'tribais', 'orais' e 'étnicas”'.

\section{O “CANTO” COMO POÉTICA}

O canto é considerado pelas nações indígenas um elemento de extrema importância para garantir a comunicação com os seres sagrados, por isso está presente na vida dos povos ancestrais em diversas situações ou, melhor dizendo, para tudo que acontece na aldeia. Ademais, algumas etnias acreditam que os cantos se originaram de povos-espírito, como fica perceptível neste relato de Fuscaldo (2016, p. 86, grifo do autor) sobre os povos A'uwe-Xavante: "Homens a'uwe explicaram também, com referência em seu conhecimento mítico, que todos os rituais e os primeiros cantos foram pegos do povo-espírito Sarewa: eles inventaram o que não existia”.

Uma das formas de acessar esses cantos é por meio dos sonhos, a saber: "Seus cantos - juntamente com os nomes, previsões, mensagens e remédios são elementos externos que podem ser acessados por intermédio do sonho e, daí, transportados para experiências não oníricas" (FUSCALDO, 2016, p. 86).

Essa concepção de canto pode justificar o motivo de algumas poetas indígenas, como Eliane Potiguara e Graça Graúna, conceituarem seus poemas como cantos, cânticos, cantares e músicas. Por exemplo, Potiguara (2004, p. 37-38), em seu poema "Migração indigena", reverbera a voz do oprimido e trata seus poemas como cânticos: "Ah!... Não sei mais continuar esses cânticos/ Porque a mim tudo foi roubado./ Se ainda consigo escrever alguns deles / Só é fruto mesmo da mágoa que me toma a alma”. Já Graúna (2007, p. 11-12), em seu poema "Canción Peregrina", entrecruza as vozes dos exilados e desterritorializados em seu próprio país por meio do canto-poema que ela elabora: "Yo canto el dollor/ deste el exilio/ tejendo um colar/ de muchas histórias / y diferentes etnias / En cada parto/ y canción de partida/ a la Madre-Tierra pido refúgio". ${ }^{4}$

Seguindo uma linha semelhante, Kambeba apresenta o canto como objeto de abordagem em seus poemas. Vale lembrar que essa autora, além de compor poemas, também compõe músicas, ou seja, a linha que separa a criação de um poema e a composição de uma música é bastante tênue. A autora define seu trabalho como litero-musical, como declarou à jornalista Jaqueline Costa (2017), do jornal $O$ Globo.

O primeiro poema que está em seu livro Ay kakyri tama (2013) recebe o mesmo título do livro, como mostrado a seguir:

4 Eu canto a dor/ deste exílio/ tecendo um colar/ de muitas histórias/ e diferentes etnias/ em cada parto/ e canção de partida/ a Mãe-Terra pede refúgio. 
Ay kakyri tama

(Eu moro na cidade)

Ay kakyri tama.

Ynua tama verano y tana rytama.

Ruaia manuta tana cultura imimiua,

Sany may-tini, iapã iapuraxi tanu ritual.

Tradução:

Eu moro na cidade

Esta cidade também é nossa aldeia,

Não apagamos nossa cultura ancestral,

Vem homem branco, vamos dançar nosso ritual.

Nasci na Uka sagrada,

Na mata por tempos vivi,

Na terra dos povos indigenas,

Sou Wayna, filha da mãe Aracy.

Minha casa era feita de palha,

Simples, na aldeia cresci,

Na lembrança que trago agora,

De um lugar que eu nunca esqueci.

Meu canto era bem diferente,

Cantava na língua Tupi,

Hoje, meu canto guerreiro,

Se une aos Kambeba, aos Tembé, aos Guarani.

Hoje, no mundo em que vivo,

Minha selva, em pedra se tornou,

Não tenho a calma de outrora,

Minha rotina também já mudou.

Em convivio com a sociedade,

Minha cara de "índia" não se transformou,

Posso ser quem tu és,

Sem perder a essência que sou.

Mantenho meu ser indigena,

Na minha Identidade,

Falando da importância do meu povo,

Mesmo vivendo na cidade (KAMBEBA, 2013, p. 25, grifo nosso).

O poema está estruturado em oito estrofes de quatro versos e possui certa regularidade em seu ritmo. A primeira estrofe está escrita na língua tupi-kambeba, sendo que essa é uma marca particular presente nos poemas da autora, o que lhes dá um caráter bilíngue, traço identitário da etnia Omágua Kambeba.

A segunda estrofe é uma tradução da primeira. Outros autores de literatura indígena optam por escrever em sua língua nativa, demonstrando, com isso, uma postura de desobediência epistemológica por resistirem à imposição da língua do colonizador e uma estratégia de sobrevivência para que suas línguas [dos indígenas] não sejam extintas, todavia também escrevem na língua portuguesa com o propósito de serem compreendidos pelos não indigenas. O eu poético 
apresenta a atual situação dos indígenas urbanos, como é possível constatar pelo uso dos verbos no presente. Para parte da sociedade brasileira, os povos ancestrais perdem sua indianidade por não viverem mais na aldeia, não andarem nus, caçando e pescando, como ficou incutido no imaginário de muitos brasileiros. Porém, a voz poética convida o não indígena para participar do seu ritual, numa atitude de respeito à alteridade, revelando que a identidade indígena pode ser preservada independentemente do local em que se vive.

A terceira estrofe, por sua vez, aborda o passado, como se percebe pelos verbos no pretérito perfeito, e nela é trazida a origem da voz que fala no poema: onde nasceu, onde viveu por muito tempo, de quem eram os territórios antes habitados, quem é ela e de quem é filha. Define-se como Wayna, que significa, em quéchua, "aquela que é jovem". Esse é o nome indigena da poeta. Sua mãe é Aracy, nome de origem guarani que significa "aurora", "mãe do dia". Já a quarta estrofe do poema caracteriza o espaço externo do seu lugar de origem: uma casa simples, feita de palha e que existe apenas em sua lembrança.

Na quinta estrofe, o canto é mencionado explicitamente para demonstrar que muitas coisas mudaram com a chegada dos colonizadores, por exemplo, a sua língua, que era do tronco tupi. Atualmente, no Brasil, há 274 linguas faladas por 305 povos, ou seja, afirmar que esse é um país monolingue é uma demonstração de desconhecimento ou de não reconhecimento das línguas faladas pelos povos ancestrais. Nesse cenário, Kambeba apresenta seu canto como um instrumento de resistência identitária e um elemento de unificação das etnias. Pelo mesmo viés, Nhenety Kariri-Xocó (2013, p. 5) alega que "na musicalidade de cada povo vive a memória de cada identidade".

$\mathrm{Na}$ sexta estrofe, é dada continuidade ao paralelo entre o tempo passado e o presente, assim a voz poética denuncia a destruição das florestas brasileiras, modificando, consequentemente, o modo de viver dos povos ancestrais. O verde das florestas cedeu lugar ao cinza das pedras, e, mesmo assim, ainda há aqueles que acreditam que é possivel aos povos indigenas sobreviverem como seus ancestrais, sem levar em conta que muitos desses grupos vivem desterritorializados. Sem território, não há florestas, não há rios, não há montanhas, não há caça, não há espíritos protetores.

Na sétima estrofe, é abordada uma das teses mais defendidas por Kambeba sempre que dá uma entrevista, aparece na mídia ou nas redes sociais: não existe cara de índio, existe uma identidade indigena que diz respeito às cosmovisões e à manutenção de hábitos e rituais realizados pelos ancestrais e que são específicos de cada etnia. Pela mesma via, Daniel Munduruku $(2018$, p. 1) assevera que "[...] apesar de minha cara de 'indio', meu cabelo de 'indio', meus olhos puxados de 'indio', as maçãs do rosto salientes de 'indio', eu não sou 'indio' [...] Eu sou Munduruku". Ou seja, mesmo em contato com os não indígenas, a poeta mantém dentro de si um jeito kambeba de ser. Outro ponto que merece destaque é a citação do mote usado pelo movimento indígena em 1970: "Posso ser quem tu és, / Sem perder a essência que sou".

$\mathrm{Na}$ última estrofe, o eu poético prossegue afirmando sua identidade, salientando que viver na cidade não o faz ser menos kambeba e menos importante do que os demais que ainda vivem na aldeia. Em vista disso, infere-se que, por meio dos seus poemas-cantos, Kambeba reafirma sua identidade e propaga a importância da interculturalidade, em consonância com o pensamento de Nhenety Kariri-Xocó (2013, p. 5) ao alegar que "os cantos são canais de afirmação e de 
revitalização. Os cantos são também canais pedagógicos para essas comunidades e para a luta pelos direitos coletivos dos povos tradicionais".

Uma das estratégias que a poeta utiliza para divulgar sua arte é por meio do sarau musical, apresentando seus poemas em forma de música, ou seja, pode-se perceber que, em sua produção artística, música e literatura não se separam, como fica evidenciado nas notícias que divulgam a participação de Kambeba em eventos.

\section{As etNias NOS POEMAS COMO MARCA DE IDENTIDADE}

A etnia Kambeba - que significa "cabeça chata" -, também conhecida como omágua - povos das águas -, é constituída por uma população de 1.500 pessoas que vivem basicamente em cinco aldeias no estado do Amazonas, conforme dados do site PIB Socioambiental. O achatamento da cabeça dos povos kambeba se dava de forma artificial com a intenção de não serem confundidos com os povos que praticavam canibalismo ${ }^{5}$. Com relação à língua, os Omágua Kambeba fazem parte do tronco linguístico tupi-guarani e ainda dominam um vocabulário significativo de sua língua nativa, porém, no cotidiano se comunicam utilizando a lingua portuguesa. Eram considerados pelos colonizadores como "mais civilizados", em comparação com os demais povos, por usarem roupas de algodão feitas por eles mesmos.

A menção das etnias nos poemas indígenas é uma estratégia utilizada frequentemente, como é visivel nos escritos de Potiguara (2004, p. 31-34), por exemplo, no poema "Ato de amor entre os povos":

[...] E os POTIGUARAS, comedores de camarão/ que HOJE - carentes -/ nos recomendarão a Tupã. / E te darão o anel do guerreiro - parceiro/ E a mim? / Me darão a honra do/ Nome/ A ESPERANÇA - meu homem!/ De uma pátria sem fim $[. .$.$] .$

E, também, nos escritos da poeta Graúna (1999, p. 40), como em seu poema "Nem mais, nem menos":

Um homem, uma mulher/ são o que são:/ palimpsestos/ pássaros/ deuses [...] Asteca/ Pankararu/ Fulni-ô/ Xavante/ Potiguara, quem sabe?/Íntimos irmãos da terra/ salvaguardam o limo das pedras/ o voo dos peixes / e os sagrados rios/ navegáveis.

Essa particularidade estética também é percebida nos poemas de Kambeba, como podemos constatar por meio do poema abaixo:

União dos povos indígenas

[...]

Pela defesa do que é nosso,

Todos os povos devem se unir,

Relembrando a bravura,

Dos Kambeba, dos Macuxi,

Dos Tembé e dos Kocama

Dos valentes Tupi Guarani

[...] (KAMBEBA, 2013, p. 35).

5 Conforme explica Kambeba em sua dissertação, disponível em: https://tede.ufam.edu.br/bitstream/tede/3978/2/Disserta\%C3\% A7\%C3\%A3०\%20-\%20M\%C3\%A1rcia\%20Vieira\%20da\%20Silva.pdf. Acesso em: 12 abr. 2020. 
O canto guerreiro da poeta convoca as diversas etnias a lembrarem a valentia de seus ancestrais e se unirem para lutar por seus direitos. Mesmo sem poder pisar em seus territórios sagrados, demonstram ter consciência de serem herdeiros de uma memória, tendo, assim, a missão de assegurar aos tanu muaryrí que essa memória não seja apagada, garantindo-lhes um futuro. Ainda que vivendo na cidade, buscam manter sua cultura e ser respeitados pelos demais.

A sociedade brasileira ainda possui uma concepção de índio genérica, e essa ideia é problemática, pois não leva em consideração a riqueza cultural de cada nação e suas diferentes necessidades. A poesia indigena, ao utilizar como recurso estético as menções das diferentes etnias, contribui para a divulgação dessa pluralidade de nações existentes no território brasileiro; além disso, o poema nos ensina a "ser críticos a essa ideia plasmada de humanidade homogênea na qual há muito tempo o consumo tomou o lugar daquilo que antes era cidadania" (KRENAK, 2019, p. 19).

Recorre-se, aqui, ao geógrafo francês Joel Bonnemaison (2002, p. 96) para conceituar o termo etnia: "pode ser concebido como o campo de existência e de cultura, vivido de modo coletivo por um determinado número de indivíduos". Em pleno território brasileiro, há 305 etnias - algumas delas em vias de extinção guerrilhando pela sua existência e para que sua cultura não seja apagada nem integrada. Vale lembrar que, quando os portugueses chegaram ao Brasil, havia mais de mil nações indígenas, porém, por onde os europeus passaram, deixaram rastros de sangue e mortandade.

Em outro poema, Kambeba faz uma homenagem a Belém, capital do estado do Pará, denominando-a como a cidade das nações indigenas, local onde coexistem diversas etnias:

\section{Belém indigena - Belém cabocla}

[...]

Belém dos Tembé

Dos Mundurucu,

Dos Amanayé,

Dos Kaxuyana

Dos Araweté

Dos TUPI guarani

Dos sateré-mawé

[...] (KAMBEBA, 2013, p. 53).

A cidade de Belém é personificada no poema de Kambeba, sendo caracterizada por meio de uma linguagem afetuosa; o espaço físico recebe os predicativos de "carinhosa", "manhosa", "dengosa", "cheirosa" e "gingosa". Trata-se da personificação da mulher indígena, da cabocla, representando a origem miscigenada do povo brasileiro, e, assim, como numa gradação, é denominada a deusa das matas. O eu poético apresenta o motivo de Belém ser considerada uma cidade mestiça: seu pertencimento a várias nações étnicas. Não é a Belém dos "indios", é a Belém de um povo que representa uma etnia específica. Mesmo com tanta diversidade, o eu lírico tem a esperança de ver esses povos unidos na luta pelo respeito a suas culturas e suas epistemes.

\footnotetext{
6 Tradução: "nossos netos" (KAMBEBA, 2013, p. 75).
} 
Realçar os aspectos particulares dessas identidades é ir de encontro a um pensamento colonial que defende a homogeneização das culturas, tendo como orientação uma perspectiva decolonial, conforme assegura Krenak (2019, p. 16):

O fato de podermos compartilhar esse espaço, de estarmos juntos viajando não significa que somos iguais; significa exatamente que somos capazes de atrair uns aos outros pelas nossas diferenças, que deveriam guiar o nosso roteiro de vida. Ter diversidade, não isso de uma humanidade com o mesmo protocolo. Porque isso até agora foi só uma maneira de homogeneizar e tirar nossa alegria de estar vivos.

A sociedade brasileira tem muito a aprender com as nações indigenas no que se refere à valorização dessa diversidade cultural. O primeiro passo para isso é estourar a bolha social que afasta uma cultura da outra, reconhecer as alteridades que coexistem nos mesmos espaços, respeitando-as, ouvindo-as e valorizando-as, permitindo-se a abertura para o novo.

Ao sobrelevar a existência de diversas nações como um recurso estético etnopoético, Kambeba parte de uma concepção que compreende a etnia como um elemento fundamental na garantia de sobrevivência de suas culturas, como sustenta Bonnemaison (2002, p. 93-94): "sem etnia bem delineada, não pode existir cultura nem visão cultural. A etnia elabora a cultura e, reciprocamente, a existência da cultura funda a identidade da etnia".

\section{O AUTORRETRATO ETNOPOÉtico OMÁGuA Kambeba}

O autorretrato é outro aspecto utilizado por Kambeba com o propósito de fotografar a identidade do seu povo. Não é à toa que, em seu livro Ay kakyri tama (2013), para cada poema há uma página com fotografias dos povos Omágua de autoria da própria poeta. Por isso, podem ser chamados de poemas-retratos, poemas-imagens e poemas-paisagens, uma vez que corporificam os cantos-versos kambeba, como é possivel verificar por meio do poema a seguir, que foi utilizado pela poeta na epígrafe de sua dissertação de mestrado:

Ser indigena - ser omágua

Sou filha da selva, minha fala é Tupi.

Trago em meu peito,

as dores e as alegrias do povo kambeba

e na alma, a força de reafirmar

a nossa identidade,

que há tempo ficou esquecida,

diluída na história.

Mas hoje, revivo e resgato a chama

ancestral de nossa memória.

Sou kambeba e existo sim:

No toque de todos os tambores,

na força de todos os arcos,

no sangue derramado que ainda colore

essa terra que é nossa.

Nossa dança guerreira tem começo,

mas não tem fim! 
Foi a partir de uma gota d'água

que o sopro da vida

gerou o povo omágua.

E na dança dos tempos

pajés e curacas

mantêm a palavra

dos espíritos da mata,

refúgio e morada

do povo cabeça chata.

Que o nosso canto ecoe pelos ares

como um grito de clamor a Tupã,

em ritos sagrados,

em templos erguidos,

em todas manhãs!

(KAMBEBA, 2013, p. 25).

A primeira estrofe retrata a identidade do indígena e, mais especificamente, do ser kambeba, conceituado como aquela que é filha da selva e traz em sua memória a língua tupi. O eu poético denuncia a realidade opressora sofrida pelo seu povo quando forçado a viver no silêncio e a negar sua etnicidade para evitar as perseguições dos opressores, como é afirmado pela própria Kambeba (2012, p. 59) em sua pesquisa de mestrado: "Seu silêncio foi uma estratégia de defesa e resistência perante a escravidão, guerras etc.". Potiguara (2004, p. 59-60), em seu poema "Tocantins de sangue", também aborda a realidade dos povos indígenas que viviam no Tocantins e, por meio do autorretrato, manifesta sua indignação no tocante às injustiças cometidas contra esses povos.

$\mathrm{Na}$ segunda estrofe do poema, o eu poético inicia revelando sua existência para a sociedade brasileira, contradizendo a ideia de que os povos kambeba foram extintos. E é por meio da resistência cultural do seu povo que essa existência é comprovada, apresentando, assim, elementos representativos da identidade omágua: sua dança e sua música, quando faz referência ao toque dos tambores; sua luta, quando faz referência à força dos seus arcos; e, por fim, sua coragem, quando faz referência ao sangue que colore a terra, dado que, para defender seus territórios tradicionais, os quais se encontram impregnados de memórias ancestrais, põem suas vidas em risco.

Ainda sobre a segunda estrofe, a voz poética exprime a origem do povo Omágua, sinalizando que surgiu da água, elemento identitário dessa etnia. Nesse ínterim, a dança é apresentada como guardiã das palavras do grande espírito da floresta, ou seja, por meio dos rituais que envolvem o canto e a dança, os Kambeba mantêm vivos sua tradição, seus costumes e suas identidades.

$\mathrm{Na}$ última estrofe, a poeta exprime seu desejo, por isso faz uso do modo verbal subjuntivo em "Que nosso canto ecoe pelos ares". Percebe-se mais uma vez a presença do canto, que, nessa acepção, é um instrumento que conecta os indígenas aos seres sagrados. Essa mesma concepção de canto faz parte da cosmogonia de outros povos ancestrais, como é possivel observar nas palavras de Antônio Risério (2018, p. 122-126) ao fazer referência à função dos poemas ou da palavra-canto dos povos Araweté: "Pelo canto, os humanos se comunicam com o outro mundo. A palavra-canto é a via de acesso araweté às paragens sobrenaturais. Religa ou ressolidariza o que um dia se rompeu para gerar o cosmos como o conhecemos". 
Pela leitura do poema, nota-se que Kambeba retrata a existência de uma nação por meio da resistência cultural dela. Assim, a autora fotografa os traços mais peculiares da identidade omágua: sua origem, seus traços físicos, sua língua, sua uka sagrada, sua dança, seu canto, sua luta, suas crenças, seus templos, seu sagrado e seu desejo de ser ouvida por Tupã e ter esses anseios atendidos - no sentido de ter sua existência reconhecida, ter voz, ser ouvida e respeitada pela sociedade brasileira.

Esse mesmo recurso estético é utilizado também por Graúna e Potiguara. A etnopoética dessas poetas desenha o retrato das populações indígenas: ora esses poemas imprimem uma fotografia de um sujeito coletivo, cultural, guerreiro e destemido, ora denunciam uma situação de indigência e exclusão provocada pelos crimes cometidos contra esses povos, suas culturas e a natureza. Esse aspecto é muito relevante na desconstrução de uma imagem estereotipada que foi construída ao longo da história, revelando à sociedade que o indigena tem e sempre teve voz e capacidade de expressar seu pensamento. As poetas constroem essa fotografia das nações indígenas, tornando-se, com isso, umas das marcas mais demonstrativas das identidades, ensinando à sociedade brasileira que "é tempo de aprendermos a nos libertar do espelho eurocêntrico onde nossa imagem é sempre, necessariamente, distorcida. É tempo, enfim, de deixar de ser o que não somos" (QUIJANO, 2005, p. 139).

\section{A PRODUÇÃo POÉtica No ESPAÇO DA FRONTEIRA}

Assim como os poemas de Potiguara e de Graúna, Kambeba também escreve num espaço de fronteira, deixando marcas estéticas explícitas e demarcando, dessa forma, seu lugar de fala. Evidencia-se que a fronteira se constitui como espaço de convergência ou divergência, rompimento ou aproximação, resistência ou assimilação. O escritor do livro O sonho de borum ${ }^{7}$ (2015), Edson Krenak, destaca a literatura nativa como uma escrita que ocorre no lugar privilegiado da fronteira: "A escrita, o oral, o romance... quando tem um livro é um romance ou narrativa? É um conto ou é um poema? É um poema ou é um canto? Então é um lugar de fronteira [...]" (KRENAK, 2012, p. 50).

Esses encontros que ocorrem nas fronteiras nem sempre trazem frutos positivos, pois algumas vezes os indigenas são acuados e não conseguem resistir às imposições culturais. Por isso a literatura nativa é uma arma importante na garantia dessa resistência. O poema "Ritual indigena", de Kambeba, revela a imposição cultural que ocorre nesse encontro forçado entre dois mundos diferentes:

Ritual indigena

[...]

O que era culto sagrado,

Guardado como ouro ancestral,

O branco achou que era pecado,

Invadiu meu ser espiritual.

Deixei de ser filha de euracy (sol)

A cruz se tornou meu sinal, 
Proibiram minha dança dizendo:

Não existe mais seu RITUAL

(KAMBEBA, 2013, p. 31).

Observa-se que esse poema apresenta marcas de uma fronteira assinalada pelo distanciamento e pela divergência entre duas culturas distintas. Ao passo que ocorre a aproximação, interpõe-se o objetivo de impor as crenças religiosas dos brancos, guiados por uma concepção de que é impossível a coexistência de mundos distintos. A declaração feita no poema é a denúncia da violência praticada pelos colonizadores. A voz poética individual representa uma realidade coletiva de uma nação que por pouco não foi dizimada por aqueles que acreditavam ser superiores e, assim, deveriam civilizar e catequizar os "outros" considerados inferiores. Essa concepção eurocêntrica perdura até os dias atuais, como é possivel notar pelo discurso do atual presidente ao defender que os povos indigenas devem ser integrados à sociedade brasileira.

É importante destacar, nesse contexto, o sentido de integração cultural. Conforme afirma o antropólogo Baniwa (2019), trata-se do abandono da língua, dos seus costumes, das suas tradições, dos seus valores, dos seus rituais e do seus modos de vida, ou seja, é se tornar um indivíduo genérico, sem identidade, sem cultura e sem direito de ocupar seus territórios tradicionais, deixando-os livres para ser explorados pelos não indigenas. Em sintese, é a extinção das nações indigenas. Assim, defender a integração dos povos indígenas à sociedade brasileira é o mesmo que defender o genocídio, o etnocídio, o ecocídio e tantos outros "cídios" que podem ocorrer com essa politica integracionista.

Retomando o poema como exemplo, tem-se que essa tentativa de eliminação cultural, no período da colonização, foi feita, e a religião representou um fator de grande importância para que os colonizadores concretizassem seu projeto de dominação. Essa imposição religiosa deu certo com vários povos, e ainda é possível perceber essa influência na atualidade, como está explícito no poema abaixo:

Aldeia tururucari-uka

[...]

Diz o tuxaua maior,

O kambeba é povo agricultor

Não se pode deixar de plantar

Escolheu São Tomé como protetor,

Para que tivesse boa colheita,

Nesse santo se apegou

[...] (KAMBEBA, 2013, p. 33).

Nesse caso, é retratada a vivência na fronteira religiosa entre o cristianismo e os rituais sagrados do povo Omágua. O Tuxaua maior é a liderança indígena, o cacique - representando a espiritualidade Omágua -, já São Tomé é um santo da igreja católica, protetor dos cegos, arquitetos e pedreiros, porém o poema acima mostra que ele foi escolhido pelos Kambeba para ser protetor da agricultura e garantir uma colheita farta.

A fronteira entre a cosmogonia indígena e o cristianismo também está presente nos poemas de Graúna (1999), como em "Gênesis" (p. 34), "Via-crúcis" (p. 41), "Dessemelhantes" (p. 46) e "Ofertório" (p. 22). Ao escrever nesse espaço de interação simbólica e tornar explícitas essas marcas de aproximação e distancia- 
mento, são fortalecidas as identidades indigenas e se permite o reconhecimento das alteridades presentes nas fronteiras, como escreve a própria Graúna (2013, p. 70): "ouvir/ intuir a voz do outro é reconhecer-se no processo de identidade e alteridade $[\ldots] "$.

\section{CONSIDERAÇÕES FINAIS}

Os aspectos presentes nos poemas de Kambeba, Graúna e Potiguara podem ser considerados como características próprias da poesia indígena que a particularizam, sendo fundamentais na constituição de uma literatura nativa brasileira com uma identidade própria.

Os poemas de Kambeba são criados por meio de uma perspectiva decolonial, inferindo-se que têm a intenção de descatequizar o olhar da sociedade para que possa enxergar a nação Omágua e outras nações indígenas, gerando uma concepção livre de preconceitos, caricaturas e estereótipos. Soma-se a isso compreender esses textos como um mecanismo de resistência à colonialidade, tendo em vista que os povos Omágua e, por extensão, os povos indigenas deste país, não aceitam as imposições feitas pelo Estado que ferem a identidade deles, bem como sua cultura, seus direitos e sua espiritualidade.

Sendo assim, a etnopoética de Kambeba pode ser concebida como um instrumento de luta pelo reconhecimento de sua existência, pela valorização de sua cultura e pelo respeito a seus direitos. Por esse viés, as escrituras indígenas se corporificam como objeto de desobediência epistemológica, pois assim fica visivel que, por mais que o pensamento eurocêntrico prevaleça, existem outras formas de compreensão de mundo que resistem, persistem, se fortalecem e ganham espaço. E, com isso, a poesia de Kambeba (2018, p. 42) cumpre seu papel, pois, conforme diz a escritora:

Quero que as pessoas, ao ler meu poema, de modo especial indigenas, sintam-se esperançosos e fortalecidos numa ancestralidade que os move e que nos move, mas sem esquecer o seu lugar de onde estão e para onde vão. Então esse trânsito é muito importante na construção de minha escrita poética porque é o que se vive.

\section{The Particularities in Márcia Kambeba's ethnopoetics}

Abstract: This article analyzes Márcia Kambeba's ethnopoetics, in her work $A y$ kakyri tama - Eu moro na cidade (2013), evaluating which mechanisms of poetic language used specify the author's way of writing, also establishing a relationship with Graça Graúna and Eliane Potiguara's "chant". The choice of Kambeba's poems as an object of study was due to by the perception that there is a very intense indigenous identity in ethnopoems, adding an aesthetic richness to it. The theoretical support for this work was given by Márcia Kambeba (2012, 2018), Daniel Munduruku (2018), Ailton Krenak (2019), and others. As a result of this investigation, it is noticed there are elements that particularize indigenous ethnopoetics, and these ones can be considered as peculiar characteristics of a writing of native peoples.

Keywords: Ethnopoetics. Márcia Kambeba. Indigenous identity. Graça Graúna. Eliane Potiguara. 


\section{REFERÊNCIAS}

AUN, H. A poeta indígena que luta pelos direitos da mulher nas aldeias. Catraca Livre, 18 abr. 2017. Disponivel em: https://catracalivre.com.br/cidadania/ poeta-indigena-que-luta-pelos-direitos-da-mulher-nas-aldeias /. Acesso em: 31 mar. 2020.

BANIWA, G. dos S. L. A visão colonialista do novo governo e o "projeto de extermínio e extinção indígena". Revista IHU (on-line), 23 abr. 2019. Disponível em: http:/ / www.ihu.unisinos.br/78-noticias / 588501-o-novo-governo-e-o-projetode-exterminio-e-extincao-indigena-entrevista-com-gersem-baniwa. Acesso em: 19 abr. 2020.

BONNEMAISON, J. Viagem em torno do território. In: CORREA, R. L.; ROSENDHAL, Z. Geografia cultural: um século (III). Rio de Janeiro: UERJ, 2002. p. 83-131.

COSTA, J. Márcia Wayna Kambeba, geógrafa: abre-se um novo papel para a mulher indigena. O Globo, Rio de Janeiro, 10 jul. 2017. Disponivel em: https:// oglobo.globo.com/sociedade/conte-algo-que-nao-sei/marcia-wayna-kambebageografa-abre-se-um-novo-papel-para-mulher-indigena-21566839. Acesso em: 2 abr. 2020.

FUSCALDO, A. I. A. Ro'wapari'nho're: sonhar e pegar cantos no xamanismo a'uwe-xavante. São Paulo: Porto de Ideias, 2016.

GRAÚNA, G. Canto mestizo. Maricá, Rio de Janeiro: Blocos, 1999.

GRAÚNA, G. Tear da palavra. Belo Horizonte: [s. n.], 2007.

GRAÚNA, G. Contrapontos da literatura indigena no Brasil. Belo Horizonte: Mazza Edições, 2013.

KAMBEBA, M. W. Ay kakyri tama: eu moro na cidade. Manaus: Grafisa Gráfica e Editora, 2013.

KAMBEBA, M. W. Fazer caber muitos mundos no mundo. Revista IUH (on-line), n. 527, p. 42-44, 2018. Entrevista concedida a Ricardo Machado, Julie Dorrico e Lenno Daner. Disponível em: http://www.ihuonline.unisinos.br/artigo/7396fazer-caber-muitos-mundos-no-mundo. Acesso em: 13 jun. 2019.

KARIRI-XOCÓ, N. Cantando as culturas indigenas. [s. 1.]: Thydêwá, 2013.

KRENAK, A. Ideias para adiar o fim do mundo. Rio de Janeiro: Companhia das Letras, 2019. Disponivel em: file:///C:/Users/gener/OneDrive/Documentos/ livros/lit.\%20ind\%C3\%ADgena/ideias-para-adiar-o-fim-do-mundo.pdf. Acesso em: 22 abr. 2020.

KRENAK, E. D. Começos da minha história. Revista Leetra Indigena, São Paulo, n. 1, p. 38-39, 2012.

MUNDURUKU, D. Tempo, tempo, tempo. Revista Coletiva, n. 1, p. 1-7, jun. 2018. POTIGUARA, E. Metade cara, metade máscara. São Paulo: Global, 2004.

QUIJANO, A. Colonialidade do poder, eurocentrismo e América Latina. In: LANDER, E. (org.). A colonialidade do saber: eurocentrismo e ciências sociais. Perspectivas latino-americanas. Buenos Aires: Clacso, 2005.

RISÉRIO, A. Palavras canibais. In: DORRICO, J.; DANNER, L. F.; CORREIA, H. H. S.; DANNER, F. (org.). Literatura indigena brasileira contemporânea. Porto Alegre: Editora Fi, 2018. p. 119-154. 
DOSSIÊ

ROTHENBERG, J. Etnopoesia no milênio. Tradução Luci Collin. Rio de Janeiro: Azougue Editorial, 2006.

SILVA, M. V. da. Reterritorialização e identidade do povo Omágua-Kambeba na aldeia Tururucari-Uka. 2012. 153 f. Dissertação (Mestrado em Geografia) - Universidade Federal do Amazonas, Manaus, 2012. 